\title{
Altered gene expression and ecological divergence in sibling allopolyploids of Dactylorhiza (Orchidaceae)
}

\author{
Ovidiu Paun ${ }^{1,2^{*}}$, Richard M Bateman², Michael F Fay², Javier A Luna ${ }^{2}$, Justin Moat ${ }^{2}$, Mikael Hedrén ${ }^{3}$ and \\ Mark W Chase $^{2}$
}

\begin{abstract}
Background: Hybridization and polyploidy are potent forces that have regularly stimulated plant evolution and adaptation. Dactylorhiza majalis s.S., D. traunsteineri s.l. and D. ebudensis are three allopolyploid species of a polyploid complex formed through unidirectional (and, in the first two cases, recurrent) hybridization between the widespread diploids D. fuchsii and D. incarnata. Differing considerably in geographical extent and ecological tolerance, the three allopolyploids together provide a useful system to explore genomic responses to allopolyploidization and reveal their role in adaptation to contrasting environments.
\end{abstract}

Results: Analyses of CDNA-AFLPs show a significant increase in the range of gene expression of these allopolyploid lineages, demonstrating higher potential for phenotypic plasticity than is shown by either parent. Moreover, allopolyploid individuals express significantly more gene variants (including novel alleles) than their parents, providing clear evidence of increased biological complexity following allopolyploidization. More genetic mutations seem to have accumulated in the older D. majalis compared with the younger $D$. traunsteineri since their respective formation.

Conclusions: Multiple origins of the polyploids contribute to differential patterns of gene expression with a distinct geographic structure. However, several transcripts conserved within each allopolyploid taxon differ between taxa, indicating that habitat preferences shape similar expression patterns in these independently formed tetraploids. Statistical signals separate several transcripts - some of them novel in allopolyploids - that appear correlated with adaptive traits and seem to play a role favouring the persistence of individuals in their native environments. In addition to stabilizing the allopolyploid genome, genetic and epigenetic alterations are key determinants of adaptive success of the new polyploid species after recurrent allopolyploidization events, potentially triggering reproductive isolation between the resulting lineages.

\section{Background}

Recent genomic investigations have uncovered signals of past whole-genome duplications (WGD) across angiosperms, indicating that polyploidy is a common mechanism of genome evolution in flowering plants $[1,2]$. Over time, polyploids undergo diploidization, eventually behaving like diploids both genetically and cytogenetically, but they retain vestiges of their WGD heritage. The prevalence of WGD across the history of flowering

\footnotetext{
* Correspondence: ovidiu.paun@univie.ac.at

'Department of Systematic and Evolutionary Botany, University of Vienna, Rennweg 14, A-1030 Vienna, Austria Full list of author information is available at the end of the article
}

plants suggests that angiosperm evolution proceeds in cycles of genome doubling and subsequent diploidization [2], which have inevitably influenced their evolutionary lineage. WGD may even have been a pivotal evolutionary force during the origin and diversification of angiosperms; by extending functional capacities [3] and creating evolutionary innovation, these WGD events are hypothesized to have been key factors stimulating major phenotypic transitions [4-6]. For example, successive duplications of several key floral organ identity genes from the MADS-box family imply that polyploidy was important for the origin and evolution of the flower, itself a diversity-enhancing feature $[7,8]$. In addition, a
C Biomed Central 
clustering of genome duplications around the Cretaceous-Tertiary (KT) boundary in independent angiosperm lineages indicates that polyploid lineages may be better able to radiate if they are fortunate enough to survive the randomness inherent in mass extinction events [9-11].

Most frequently, WGD arises from meiotic non-reduction followed by the fusion of unreduced gametes, commonly via a 'triploid bridge' [12]. Ramsey \& Schemske [12] reported that unreduced gametes are produced at rates on average $c a 50$ times higher in hybrids than in non-hybrid lineages. As a result, hybridization and WGD appear to be closely associated in angiosperms, so that evolutionarily successful polyploidization events appear especially prevalent among hybrids [[13], p. 329, [14-16]]. Autopolyploids are nonetheless widespread in nature $[17,18]$, and many remain phenotypically hidden within their diploid parent.

The association of WGD and hybridization may provide several adaptive advantages to an evolutionary lineage. By combining entire parental genomes in the same nucleus, polyploid hybrids potentially benefit at meiotic pairing. They also gain from hybrid vigour and transgressive traits (outside the parental range $[19,20]$ ), avoiding problems specific to homoploid hybrids such as segregation and breakdown in $F_{2}$ generations [21]. Additionally, WGD provides allopolyploids with a high degree of post-zygotic reproductive isolation from their diploid relatives [12]. Polyploidy doubles gene number, creating the potential for buffering vital functions (perhaps via homogenization [22]) but also for functional divergence (neofunctionalization), which increases biological complexity [23]. Other proposed advantages of polyploidy relate to relaxation of reproductive system requirements, via loss of self-incompatibility [24] and/or potential for agamospermy $[21,25]$. By perpetuating the most adaptive hybrid genotypes, allopolyploidy can result in abrupt or even saltational speciation [26]. However, many neopolyploids will still fail to become established because of reproductive failure [27] and/or minority cytotype disadvantage [28]. Stebbins [29] extrapolated from well-studied genera that $c a 30 \%$ of all angiosperm species may be functional allopolyploids. In any case, speciation via polyploidy is likely to be a major mode of sympatric speciation in plants [14,30]; recent direct estimates indicate that as many as 15\% of angiosperm speciation events are accompanied by WGD [31].

Because of the increased gene and genome dosage, neopolyploids usually suffer from negative effects of expression redundancies, regulatory incompatibilities and meiotic abnormalities [21,32]. Hence, allopolyploidy induces a state of 'genome shock' [33], allowing natural selection to prevent establishment of any maladaptive early-generation polyploid. Exceptions have been also reported: for example wheat synthetic allopolyploids show additivity of expression [34], while in newly synthesized Gossypium allopolyploids there is little evidence of genomic shock [35]. However, most of the successful early-generation allopolyploids have to accommodate the two divergent genomes in one nucleus by adjusting organization and function of both genomes through genetic and epigenetic alterations [32,36-38]. Several studies conducted on resynthesized hybrids/allopolyploids (e.g. [39-44]) and wild neopolyploids (e.g. [45-47]) have revealed that hybridization, with or without a shift in ploidy, can quickly result in alterations of gene expression due to gene loss, silencing, subfunctionalization (tissue-specific expression of gene copies) and other non-additive expression patterns. More than one type of alteration has been recorded in most cases of polyploidy that have been studied in sufficient detail. Epigenetic changes, such as gene silencing via DNA methylation change and chromatin remodeling, appear to be a more universal response that, if stably inherited, can rapidly lead to subfunctionalization [36] or to phenotypic differences in recurrent allopolyploids [48].

Despite our increasing general knowledge of polyploidy and hybridization, information remains limited on the links between genomic responses to allopolyploidization and mechanisms involved in shaping long-term adaptive capacities in natural allopolyploid populations. We lack a detailed understanding of the scope of expression changes and how they function within established natural lineages. For example, we still need to understand the functional correlations between altered gene expression and the development of adaptive phenotypes and to determine their effects on ecological and reproductive isolation and ultimately on evolution of polyploid lineages. We aim here to investigate gene expression alterations in three established, sibling allotetraploid $(2 n=80)$ species of the Dactylorhiza majalis (Rchb.) P.F.Hunt \& Summerh. complex (Orchidaceae: Orchidinae) and to correlate these alterations with their respective ecological preferences (Figure 1).

The widespread allotetraploids $D$. majalis s.s. and D. traunsteineri s.l. have each been derived iteratively at different times during the last part of the Quaternary; together with the narrowly endemic D. ebudensis, they originated through unidirectional hybridization between the diploids $(2 n=40) D$. fuchsii (in all cases the maternal parent) and D. incarnata ([49] and references therein). Despite their largely shared genetic heritage, the three allotetraploids differ significantly in morphology, ecology and geography (Figure 1). Comparison of the degree of concerted evolution in ITS alleles, the cohesiveness of epigenetic patterns of individuals from different regions [48], and the patterns of morphology and ecological preference together suggest that $D$. majalis s.s. is 


\begin{tabular}{|c|c|c|c|c|c|c|c|}
\hline \multirow[t]{2}{*}{ Species } & \multicolumn{2}{|c|}{ Soil pH } & \multicolumn{2}{|c|}{ Soil moisture } & \multicolumn{2}{|c|}{ Shade tolerance } & \multirow[t]{2}{*}{ Distribution } \\
\hline & 56 & 78 & Low & High & Low & Moderate & \\
\hline D. incarnata s.l. & - & $\mathbf{E}$ & & & & $\boldsymbol{\theta}$ & $\mathrm{N}+\mathrm{C}$ Europe, $\mathrm{W}$ Asia \\
\hline D. fuchsii & & & & & & & $\mathrm{N}+\mathrm{C}$ Europe, $\mathrm{W}$ Asia \\
\hline D. majalis & & 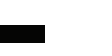 & & & & & $\mathrm{NC}+\mathrm{EC}$ Europe \\
\hline D. traunsteineri ${ }^{1}$ & & & & E & & & Britain, Scandinavia, Alps \\
\hline D. ebudensis & & $\mathbf{m}$ & & $\mathbf{a}$ & 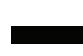 & & NW Scotland (N Uist) \\
\hline
\end{tabular}

substantially more derived and genetically homogeneous. It is therefore hypothesized to be the oldest of the three allotetraploids and is presumed to have passed through glacially induced bottlenecks in southern Eurasia [48,49]. It has a comparatively wide ecological tolerance of soil moisture (Figure 1) and presently occurs in damp meadows and fens from western and central Europe to southernmost Scandinavia. In contrast, $D$. traunsteineri s.l. is a more recently evolved set of allotetraploids that is more heterogeneous, both genetically [49-51] and epigenetically [48], and often still maintains both parental ITS alleles. It includes lineages that probably originated postglacially, and at present shows a more localized and disjunct distribution in northwestern and central Europe. It generally has narrow tolerances of soil moisture, being vulnerable to drought, and grows in fens and marshes. A third allotetraploid, D. ebudensis, is a narrow endemic (at present, 99\% of known individuals form a single extensive metapopulation in northwestern Scotland); it is considered to be as young as, or younger than, $D$. traunsteineri [48-50]. The coastal dune habitat that confines D. ebudensis indicates its relatively narrow substrate tolerances - notably, in the amount of groundwater, its degree of oxygenation and $\mathrm{pH}$ (Figure 1). Despite the fact that their distribution ranges partly overlap, the three polyploid taxa have different overall ecological requirements (Figure 1) and are parapatric, rarely co-occurring within the same site.

Dactylorhiza offers an excellent model system for studying successful allopolyploidy because: (i) the tetraploid taxa have a recent history of allopolyploidization but have already become well established; (ii) the parental species involved (but not necessarily the exact parental genotypes) remain extant; (iii) D. majalis and $D$. traunsteneri originated from the same parental species pair and each has multiple origins, thereby providing natural replicates for study; and (iv) all three taxa differ in habitat preferences, morphology, age and evolutionary history. Overall, this is a suitable study system to uncover mechanisms of (local) adaptation to divergent environments following polyploidy and hybridization, which are assumed to lead to evolutionary diversification and speciation. A recent investigation [48] of these Dactylorhiza allopolyploids using MSAP (methylation sensitive amplified polymorphism) demonstrated that divergent selection acts on epigenetic characters and results in differentiation that correlates with adaptation to distinct environments. We show here that similar trends are visible in the expressed patterns of the allopolyploids, and we conclude that ecological divergence between these polyploid lineages resides mainly in quantitative expression differences.

\section{Methods}

\section{Plant material}

Several individuals of each allopolyploid species, together with representatives of the diploid parental species, were sampled from four geographic regions (Table 1): the eastern Alps and Scandinavia, where D. majalis and $D$. traunsteineri grow in parapatry; northern Pyrenees, where only $D$. majalis occurs; and Britain, where D. traunsteineri s.l. occurs (plus D. ebudensis on the remote island of North Uist in northwestern Scotland). Plants were transplanted in the cold glasshouse of the Royal Botanic Gardens, Kew (U.K.), where they were grown in uniform conditions for one year to allow acclimatization prior to leaf sampling. The allopolyploid (but not the diploid) samples included here have been previously analysed epigenetically using the MSAP technique [48]. Before the transcriptomic analyses, each plant 
Table 1 Details of Dactylorhiza samples investigated in the present study

\begin{tabular}{|c|c|c|c|c|c|}
\hline Ploidy & Species & Latitude/longitude & Collector $^{1}$ & ITS alleles (ratio) $^{2}$ & Haplo type $^{2}$ \\
\hline \multirow[t]{5}{*}{$2 x$} & D. fuchsii (Druce) Soó & $42.829 / 1.995$ & $C, F, P, L$ & III (66\%): V (33\%) & $B$ \\
\hline & & $43.212 / 0.830$ & $C, F, P, L$ & V (55\%): III (45\%) & A \\
\hline & & $46.301 / 14.435$ & $P$ & V (60\%): III (40\%) & A \\
\hline & D. incarnata (L.) Soó & $42.829 / 1.995$ & $C, F, P, L$ & $X(100 \%)$ & $E$ \\
\hline & & & & $X(100 \%)$ & E \\
\hline \multirow[t]{11}{*}{$4 x$} & D. majalis (Rchb.) P.F. & $42.829 / 1.995$ & $C, F, P, L$ & III (66\%): V (33\%) & B \\
\hline & & & & III (50\%): V (50\%) & B \\
\hline & Hunt \& Summerh. & $47.596 / 15.294$ & $P$ & III (50\%): V (50\%) & C \\
\hline & & $47.905 / 14.166$ & $\mathrm{P}$ & III (50\%): V (50\%) & A \\
\hline & & $55.817 / 12.933$ & $\mathrm{H}$ & III (80\%): V (20\%) & A \\
\hline & & & & III (80\%): V (20\%) & C \\
\hline & D. traunsteineri (Saut. ex Rchb.) & $57.417 / 18.323$ & $\mathrm{H}$ & III (40\%): V (30\%): X (30\%) & $C$ \\
\hline & Verm. & $54.265 /-0.701$ & $C, F, P$ & X (50\%): V (30\%): III (20\%) & $C$ \\
\hline & & $57.436 /-5.801$ & B & III (90\%): X (10\%) & C \\
\hline & D. ebudensis (Wief. ex R.M. Bateman \& Denholm) P. Delforge & $57.663 /-7.225$ & B & V (55\%): III (30\%): X (15\%) & C \\
\hline & & & & V (55\%): III (30\%): X (15\%) & C \\
\hline
\end{tabular}

${ }^{1}$ Collectors: B - RM Bateman; C - MW Chase; F - MF Fay; H - M Hedrén; L - L Civeyrel; P - O Paun.

${ }^{2}$ Following [49].

was genotyped using nuclear and plastid markers (following [49]) to confirm that it conformed to type (Table 1).

\section{cDNA-AFLP technique}

Being based on mRNA, this method analyzes only the transcribed regions of the genome. However, transcript polymorphism, as identified by cDNA-AFLP, may not necessarily represent expression differences; apart from gene silencing, physical loss and non-synonymous polymorphism (indels, substitutions and rearrangements), synonymous substitutions can also be visible to this method $[37,48]$. However, due to the relatively recent origin and similar genetic background of the allopolyploids (see above), most of the variation depicted with cDNA-AFLPs is predicted to reflect expression differentiation of parental homeologs rather than polymorphism at the nucleotide level in exons. Gene expression can also be regulated at a later, post-transcriptional stage $[52,53]$. Parts of this level of regulation could be invisible to the cDNA-AFLP technique. Finally, the cDNAAFLP fragments will contain, in addition to coding sequence, the untranslated sections (5' and 3' UTRs) that characterize all mRNA strands. Although non-coding, the UTRs are expected to experience selection because they provide signals and binding sites for elements post-transcriptionally affecting mRNA stability or translation [54].

The standard AFLPTM procedure [55] was performed on a pool of cDNAs $[37,56]$ generated from leaves sampled from Dactylorhiza plants grown in uniform conditions at RBG Kew as previously reported [48]. The products of 27 primer combinations (of the general type EcoRI AX [+fluorescent dye]-MseI CYZ, where X, Y and Z are different selective nucleotides) were suspended in formamide and run on a capillary sequencer ABI 3100 (Applied Biosystems), together with GeneScan ROX 500 (Applied Biosystems) internal size standard. Blind samples and two replicates $(13 \%$ of total samples identifying an error rate of $0.8 \%)$ were included in all steps to test for contamination and reproducibility [57]. Fragments in the range 50-490 bp were aligned using ABI PRISM GeneScan 2.1 Analysis Software (Applied Biosystems) and visualized, scored and exported as binary presence/absence matrix using Genographer 1.6.

\section{Data analyses}

To investigate the structure of the allopolyploid transcriptome, we first assigned the cDNA-AFLP fragments transcribed from the polyploid genomes according to their status within the diploid individuals. Four categories of fragments have been traced: (i) transcripts characteristic of the maternal species, D. fuchsii, (ii) fragments specific for the paternal D. incarnata, (iii) fragments shared by the parents, and (iv) markers absent from parental species but present in allopolyploids (i.e. "novel" fragments). The average frequency of the different categories of AFLP fragments present in the allopolyploid genomes is presented as a bar-chart (Figure 2).

In all further analyses, any monomorphic fragments and those present or absent from all but one individual were removed to avoid biased parameter estimates [57]. To visualize the pattern of expression differentiation, we 


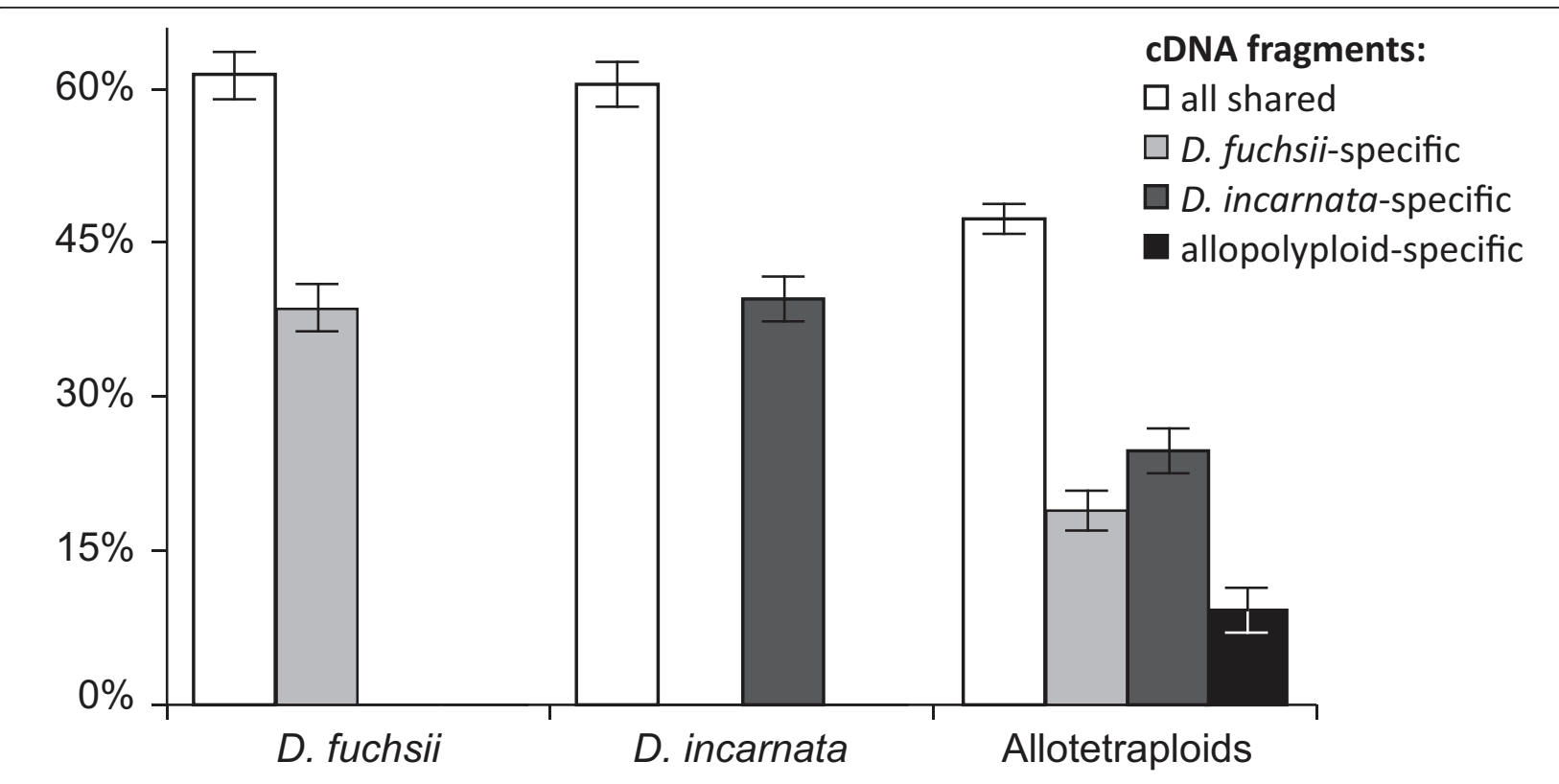

Figure 2 Average frequencies of CDNA-AFLP fragments in Dactylorhiza allotetraploids and their diploid parental species. White bars indicate shared fragments between the two parentals; light grey bars, markers characteristic of $D$. fuchsii; dark grey, markers characteristic of $D$. incarnata; the black bar shows the unique markers for allopolyploids. The error bars represent standard deviation for mean (see also Table 2).

constructed a principal coordinates analysis (PCoA) using the program package NTSYS-pc 2.02h [58]. A matrix of between-individual Dice [59] similarities constructed using the module 'SimQual' was transformed into a scalar form with 'Dcenter', on which we computed the eigenvectors and plotted them using 'Eigen'. The Dice algorithm, which does not treat shared band absence as homologous, was chosen because absence of cDNA-AFLP fragments can result from various causes, possibly involving silencing of a particular homeolog, DNA sequence polymorphism or even developmental differentiation (despite all steps taken to avoid such differentiation). We further estimated the goodness of fit of the PCoA by generating a model distance matrix from the eigenvector matrix (using 'Simint') and comparing it with the original Dice coefficient matrix (with 'Mxcomp' and 1000 permutations). For allopolyploid individuals only, a neighbor-joining (NJ) dendrogram based on the between-individuals genetic distance of Nei \& Li [60] was generated and bootstrapped [61] using 1000 replicates with Treecon 1.3b [62].

To identify particular transcripts that are selected within allopolyploid individuals by native environmental conditions, and may therefore play a role favouring their presence in a given landscape, we performed multiple univariate logistic regressions, as implemented in the spatial analysis method (SAM) proposed by Joost et al. $[63,64]$. This method goes beyond simply identifying genetic loci associated with native ecological conditions, as it also delivers hypotheses regarding the physical factors that could exert a relevant selection pressure in a particular environment. As SAM takes the individual as the reference unit, the analysis functions independently of any notion of population and is largely assumption-free [63]. For this purpose, we have started from a GIS-based ecoclimatic dataset containing 19 bioclimatic parameters from Worldclim (http:// www.worldclim.org/bioclim[65]), plus yearly averages for vapour pressure (VapPress, in $\mathrm{hPa}$ ), percentage cloud cover, number of annual days with ground frost, and maximum sunlight hours (Sunp, in \%) for March (III), April (IV), May (V), June (VI) and July (VII), all abstracted from the IWMI Climate and Water Atlas http://waterdata.iwmi.org. We performed an initial check for correlations between the 27 variables with Spearman (two-tailed) bivariate correlations and SPSS 10.0 , and the parameters involved in the largest number of correlations were excluded sequentially until no correlation remained. Therefore, for SAM analyses only seven ecoclimatic variables have been retained: BIO1 annual mean temperature, BIO8 - mean temperature of wettest quarter, BIO13 - precipitation of wettest month, BIO16 - precipitation of wettest quarter, VapPess, and Sunp III (i.e. for March) and SunpVII (i.e. for July). Finally, for the SAM analyses, each particular cDNA-AFLP pattern was retained only once (resulting in a dataset of only $87 \mathrm{cDNA}$ markers), to minimize the number of comparisons performed. 
As a measure to control for type 1 errors in multiple comparisons, SAM uses a Bonferroni corrected level of significance [63]. Despite its popularity, this procedure has recently been criticised mainly as being overly stringent [66-68]. Due to the low sample sizes that characterize the expensive cDNA-AFLP method, we expected low statistical power in our analyses. However, as we targeted only coding regions, the chances of identifying signals of selection by chance alone should be much lower than in genomic studies. We chose here not to incorporate Bonferroni corrections but rather to use the alternative false discovery rate procedure (FDR [69]), which controls for the proportion of significant results instead of controlling for single errors. We used the $\mathrm{R}$ package QVALUE [70] to adjust $P$-values derived from SAM into corresponding $Q$-values assigning a measure of significance to each of the 609 tests simultaneously performed by SAM. In addition, we used SPSS 10.0 to calculate Spearman's $r_{s}$ for the paired cDNA markers and environmental parameters involved in significant regressions, as a way to report effect size, following the recommendations of [68].

\section{Results}

\section{Gene expression in diploid and polyploid Dactylorhiza}

The 27 AFLP primer combinations yielded 305 unambiguous cDNA fragments; of these, $32 \%$ were monomorphic among all (diploid and polyploid) individuals analyzed. Within allopolyploids only, 55\% of the 291 transcribed fragments were monomorphic. However, all individuals showed distinct transcript profiles. The cDNA-AFLP data matrix and input file for SAM have been lodged in the Dryad Digital Repository at http://dx. doi.org/10.5061/dryad.8795 and it is also available as Additional file 1.

Across the cDNA-AFLP dataset there was a remarkably similar number of fragments characteristic of either parent: 74 markers were specific for D. fuchsii and 75 for $D$. incarnata, which contributed to a total transcript differentiation between the diploid parental species of 58\% (Table 2, Figure 2).

The allopolyploid transcriptome (Table 2, Figure 2) consists of $17-24 \%$ maternal (i.e. of D. fuchsii origin), $22-27 \%$ paternal (i.e. inherited from $D$. incarnata) and 45-50\% non-specific transcripts (i.e. shared by the two parents). Many of the inherited patterns are represented by fixed transcripts within the allopolyploids. Approximately $9 \%$ of the cDNA markers in allopolyploid taxa have been inherited from the maternal progenitor and are expressed by each allotetraploid individual, and 16\% are fixed within the allopolyploids and have been inherited from the paternal parent.

As much as $7-13 \%$ of allopolyploid transcripts appear to be novel (Table 2, Figure 2), but none represents a
Table 2 Transcriptomic patterns in Dactylorhiza samples investigated in the present study

\begin{tabular}{|c|c|c|c|c|c|c|c|}
\hline \multirow[b]{2}{*}{ Ploidy } & \multirow[b]{2}{*}{ Species } & \multirow[b]{2}{*}{ Region } & \multicolumn{5}{|c|}{ CDNA-AFLP } \\
\hline & & & $\mathrm{N}_{\text {ind }}$ & $N_{\text {frag }}$ & $\mathrm{F} \%$ & $1 \%$ & A\% \\
\hline \multirow[t]{5}{*}{$2 x$} & D. fuchsii & Pyrenees & 1 & 168 & $40 \%$ & - & - \\
\hline & & & 1 & 162 & $36 \%$ & - & - \\
\hline & & Alps & 1 & 177 & $40 \%$ & - & - \\
\hline & D. incarnata & Pyrenees & 2 & 181 & - & $41 \%$ & - \\
\hline & & & & 177 & - & $38 \%$ & - \\
\hline \multirow[t]{11}{*}{$4 x$} & D. majalis & Pyrenees & 2 & 234 & $24 \%$ & $22 \%$ & $9 \%$ \\
\hline & & & & 218 & $18 \%$ & $22 \%$ & $10 \%$ \\
\hline & & Alps & 1 & 239 & $19 \%$ & $26 \%$ & $10 \%$ \\
\hline & & & 1 & 231 & $19 \%$ & $26 \%$ & $7 \%$ \\
\hline & & Scandinavia & 2 & 231 & $18 \%$ & $27 \%$ & $8 \%$ \\
\hline & & & & 227 & $19 \%$ & $27 \%$ & $7 \%$ \\
\hline & D. traunsteineri & Scandinavia & 1 & 226 & $19 \%$ & $27 \%$ & $7 \%$ \\
\hline & & Britain & 1 & 221 & $19 \%$ & $24 \%$ & $9 \%$ \\
\hline & & & 1 & 211 & $17 \%$ & $26 \%$ & $8 \%$ \\
\hline & D. ebudensis & Britain & 2 & 223 & $17 \%$ & $23 \%$ & $13 \%$ \\
\hline & & & & 223 & $18 \%$ & $22 \%$ & $13 \%$ \\
\hline
\end{tabular}

$\mathrm{N}_{\text {ind }}$ - number of individuals analyzed. $\mathrm{N}_{\text {frag }}$ - number of fragments per profile; $\mathrm{F} \%, 1 \%, \mathrm{~A} \%$ - percentage of diagnostic transcripts of $D$. fuchsii, D. incarnata and allopolyploids.

repeatable event across all of the inferred independent allopolyploidization events. Finally, relatively few fragments (5.3\% from $D$. fuchsii and $2.3 \%$ from $D$. incarnata) occur in parental species but are missing from all allopolyploids; these absences may represent repeatable events of gene loss and silencing (although they may also include synonymous restriction site changes). A much larger fraction of the parental transcriptome has been silenced/lost in at least one polyploid individual (32\% from the $D$. fuchsii transcript pool and $22 \%$ from D. incarnata).

\section{Taxonomic and geographic transcriptomic differentiation} The three-dimensional PCoA (Figure 3A) of cDNAAFLP phenotypes shows clear separation of the two diploid species and of the allopolyploids, which occupy an intermediate position between the parental species along the first axis; this describes a substantial $43 \%$ of the variation present in the data matrix. The second axis of variation (16\% of the signal) separates the representatives of diploid parental species and the allopolyploid group, but places the latter outside the parental range. The three allopolyploid species are clearly separated from each other by the third axis (containing 9\% of the signal), whereas the combined information of the three factors separates the four corresponding geographical provenances for the allopolyploids. The goodness-of-fit analysis of the scatter-plot indicated a matrix correlation value of $\mathrm{r}=0.95$ at $P=0.001$ (one-tailed probability). 


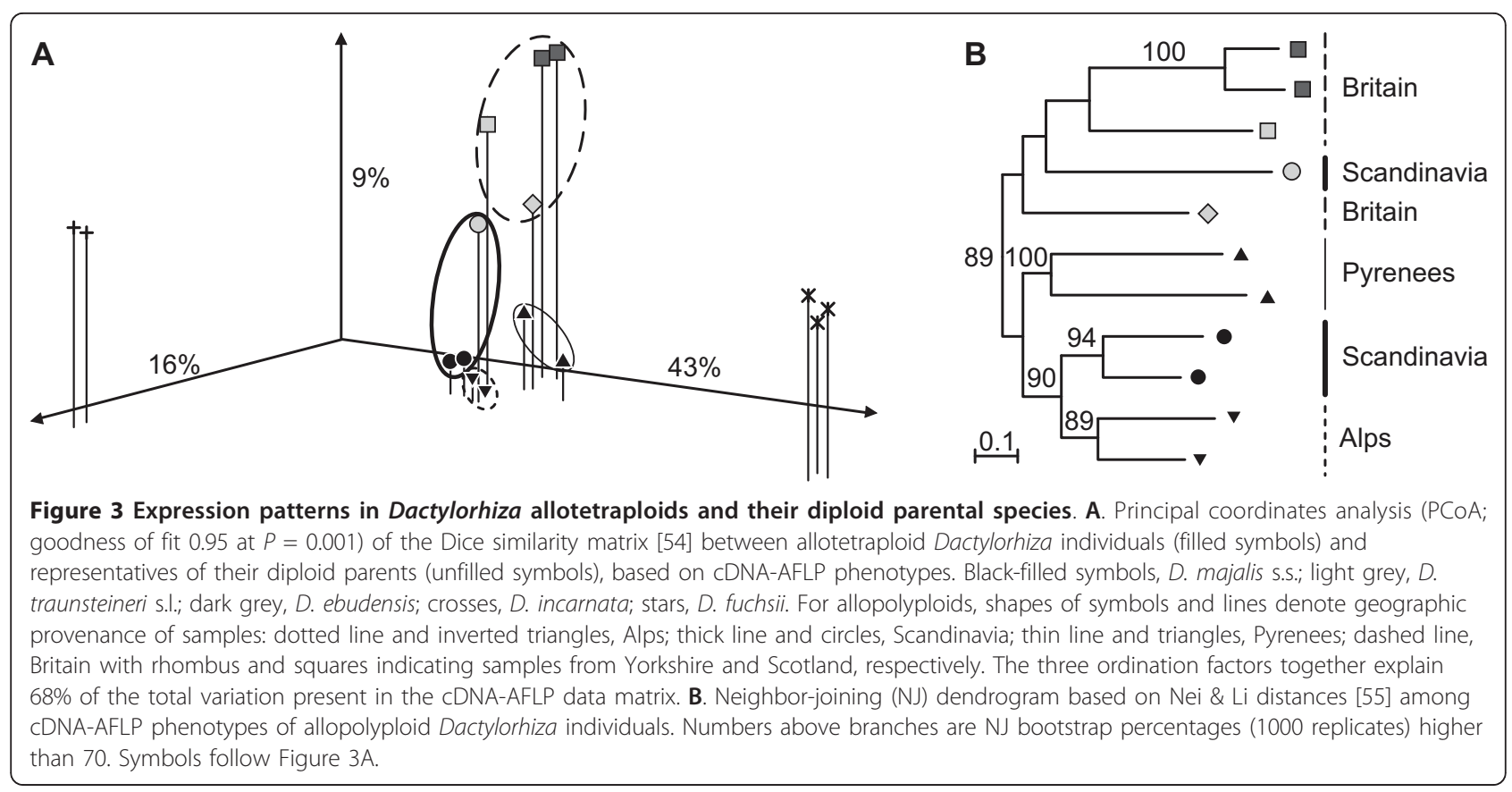

In the $\mathrm{NJ}$ analysis of allopolyploid individuals (Figure 3B), two major phylogroups are separated with $89 \%$ bootstrap support (BS): one formed by accessions of $D$. majalis and the other formed by $D$. traunsteineri plus the phenotypically similar D. ebudensis. Therefore, $D$. traunsteineri appears as a paraphyletic group, although this relationship receives low bootstrap support (BS $<70 \%$ ). Within D. majalis, the Scandinavian and Alpine accessions studied here form a well-supported subgroup (BS 90\%).

\section{Polyploid adaptive segregation}

The univariate logistic regressions corresponding to the Wald test (as implemented in SAM) reached the maximum number of iterations before the maximum likelihood equation had been solved; they were therefore discarded, following the recommendations of Joost et al. [63,64]. The alternative test implemented in SAM, the likelihood ratio or G statistical test, identified 115 (19\% of the total) regressions with $P$-values lower than 0.05 . However, after adjusting the level of significance of multiple tests with the FDR procedure, only 39 ( $6 \%$ of the total) regressions remained significant with $Q$-values of significance lower than 0.05 (Table 3). Due to partial correlation between the environmental parameters, the 39 significant correlations involve 27 adaptive markers. Notably, several of these transcripts represent novel fragments in allopolyploids (Table 3).

\section{Discussion}

The cDNA-AFLP technique provides a useful tool for investigating gene expression alterations following genome doubling and/or hybridization [45], especially in non-model systems that lack welldeveloped genomic resources. However, its expense and the type of data produced (i.e. anonymous and not quantitative) render the approach less desirable when it is compared with more recently developed technologies such as digital transcriptomics (mRNAseq [71]).

In the present study, we detected a high level of transcript differentiation (Table 2, Figure 2) between the two diploid progenitor species, which proved instrumental for further analyzing the transcriptome of allopolyploids. The high differentiation between the parental transcriptomes is consistent with several studies based on other molecular markers, which have recorded wide genetic divergence between $D$. fuchsii and D. incarnata [49,72]. Phylogenetic analyses of Dactylorhiza using nrDNA sequences of both internal and external transcribed spacers and the intron of the plastid gene rpl16 also indicated that $D$. fuchsii and D. incarnata are well differentiated and placed in separate, distinct clades [49,73-75].

\section{Allopolyploid transcriptomic content}

Our investigation of the transcriptomic composition of sibling allopolyploid Dactylorhiza species (Table 2, Figure 2) indicated that, although allopolyploid transcriptomes are largely expressing parental genes, a significant degree of novelty also exists. Given the age of the polyploidization events (most probably few to several thousand years), the presence of transcripts specific for 
Table 3 Transcriptomic patterns under environmental selection

\begin{tabular}{|c|c|c|c|c|c|c|}
\hline \multirow[t]{2}{*}{ cDNA fragment ${ }^{1}$} & \multirow[t]{2}{*}{ Fragment present always and only $\mathrm{in}^{2,3}$} & \multirow[t]{2}{*}{ Environmental factor ${ }^{4}$} & \multicolumn{2}{|l|}{$\mathrm{G}$ test } & \multicolumn{2}{|c|}{ Spearman test } \\
\hline & & & $P$-value & Q-value & $r_{\mathrm{s}}$ & $P$-value \\
\hline \multirow[t]{2}{*}{$\overline{M 41}$} & $D m$ & $\mathrm{BIO8}$ & 0.000099 & 0.0103 & 0.87 & 0.0005 \\
\hline & & SunpVII & 0.0022 & 0.027 & 0.64 & 0.03 \\
\hline $\mathrm{M} 16$ & Dm from Alps and Scandinavia & $\mathrm{BlO} 8$ & 0.00015 & 0.0103 & 0.84 & 0.001 \\
\hline \multirow[t]{2}{*}{$\underline{\mathrm{M} 59}$} & Britain (Dt and De) & $\mathrm{BlO} 8$ & 0.00015 & 0.0103 & -0.84 & 0.001 \\
\hline & & SunpVII & 0.00015 & 0.0103 & -0.85 & 0.001 \\
\hline \multirow[t]{2}{*}{ M38 } & Dm from Alps and & VapPres & 0.00015 & 0.0103 & -0.84 & 0.001 \\
\hline & Scandinavia & Sunplll & 0.00015 & 0.0103 & 0.85 & 0.001 \\
\hline $\mathrm{M} 12$ & - & $\mathrm{BlO1}$ & 0.00033 & 0.0108 & -0.78 & 0.005 \\
\hline M82 & - & $\mathrm{BlO} 8$ & 0.00033 & 0.0108 & -0.78 & 0.005 \\
\hline M4 & Scandinavia (Dm and $D t)$ & $\mathrm{BIO13,} \mathrm{BIO16}$ & 0.00033 & 0.0108 & -0.78 & 0.005 \\
\hline M37 & - & Sunplll & 0.00033 & 0.0108 & 0.79 & 0.004 \\
\hline M43 & - & SunpVII & 0.00033 & 0.0108 & 0.79 & 0.004 \\
\hline $\mathrm{M} 58$ & Scotland (Dt and De) & SunpVII & 0.00033 & 0.0108 & -0.79 & 0.004 \\
\hline $\mathrm{M} 18$ & - & $\mathrm{BlO} 8$ & 0.00043 & 0.013 & 0.84 & 0.001 \\
\hline M62 & - & SunpVII & 0.0011 & 0.017 & -0.79 & 0.004 \\
\hline $\mathrm{M} 1$ & Dt from Britain & Sunplll & 0.0012 & 0.017 & -0.68 & 0.02 \\
\hline M33 & Pyrenees $(D m)$ & SunpIII, SunpVII, BIO1 & 0.0012 & 0.017 & 0.68 & 0.02 \\
\hline M65 & All except Pyrenees & SunpIII, SunpVII, BIO1 & 0.0012 & 0.017 & -0.68 & 0.02 \\
\hline $\mathrm{M} 10$ & Alps (Dm) & BlO1, VapPres & 0.0012 & 0.017 & -0.68 & 0.02 \\
\hline $\mathrm{M} 80$ & All except Alps & BIO1, VapPres & 0.0012 & 0.017 & 0.68 & 0.02 \\
\hline $\mathrm{M3}$ & Dm from Scandinavia & $\mathrm{BlO} 8$ & 0.0012 & 0.017 & 0.68 & 0.02 \\
\hline M84 & - & $\mathrm{BIO13,} \mathrm{BIO16}$ & 0.0012 & 0.017 & -0.68 & 0.02 \\
\hline M44 & All except De & VapPres & 0.0012 & 0.017 & -0.68 & 0.02 \\
\hline M57 & De & VapPres & 0.0012 & 0.017 & 0.68 & 0.02 \\
\hline M29 & - & VapPres & 0.0015 & 0.019 & -0.75 & 0.008 \\
\hline \multirow[t]{2}{*}{ M39 } & - & SunpVII & 0.0015 & 0.019 & 0.76 & 0.007 \\
\hline & & VapPres & 0.0044 & 0.048 & -0.79 & 0.004 \\
\hline M61 & - & SunpVII & 0.0015 & 0.019 & -0.76 & 0.007 \\
\hline M36 & - & Sunplll & 0.0022 & 0.027 & 0.72 & 0.01 \\
\hline $\mathrm{M} 20$ & - & $\mathrm{BlO} 8$ & 0.0041 & 0.045 & 0.79 & 0.004 \\
\hline$\overline{M 32}$ & - & $\mathrm{BlO} 8$ & 0.0041 & 0.045 & 0.79 & 0.004 \\
\hline
\end{tabular}

Details of the 27 cDNA-AFLP patterns most likely to drive adaptation to divergent environments, together with the corresponding environmental variables involved, as indicated by the likelihood ratio (G) test implemented in SAM [58]. Significance measurements for the regressions have been adjusted for multiple testing into $Q$-values according to Storey [70]. We report here only relationships with $Q$ values $<0.05$. As a way to report effect size for each significant regression we also report Spearman's $r_{\mathrm{s}}$, following recommendations of Nakagawa [68]. Several environmental parameters show a degree of correlation, complicating attempts to identify the variable that may exert greatest selective pressure. The underlined markers are novel in allopolyploids (i.e. absent from the parents).

${ }^{1}$ For details on cDNA-AFLP markers see http://dx.doi.org/10.5061/dryad.8795 or additional file 1 .

${ }^{2}$ The patterns reported in this column refer only to polyploidy individuals.

${ }^{3} \mathrm{Dm}$ - D. majalis; De - D. ebudensis; Dt - D. traunsteineri.

${ }^{4} \mathrm{BIO} 1$ - annual mean temperature; $\mathrm{BIO} 8$ - mean temperature of wettest quarter; $\mathrm{BIO} 13$ - precipitation of wettest month; BIO16 - precipitation of wettest quarter; VapPres - yearly averages for vapour pressure (in hPa); Sunplll - \% of maximum sunlight hours in March; SunpVII - \% of maximum sunlight hours in July.

allotetraploids and the absence of some markers specific for either parent may reflect post-allopolyploidization evolution of the parental species or incomplete sampling within parental groups. However, at least some of the novel patterns may have resulted from recombination between parental homeologs or from accumulation of mutations in sequences of polyploids [38,76]. In the (most probably) hundreds of generations since the allopolyploid formation, such novel transcripts must have already proved adaptive in their genomic (i.e. internal) and environmental (i.e. external) context and have been retained by natural selection (see also below). The novel fragments are much more common in these established allotetraploid lineages of Dactylorhiza, compared with the rather limited 
proportion (ca 1\%) of non-additive transcripts identified using the same method in the Tragopogon miscellus neopolyploids (less than 80 years old; [45]). In contrast, the percentage of parental fragments that are missing in the allopolyploids resembles figures reported in other systems; for example, the transcriptome of allotetraploid cotton lacks $c a 25 \%$ of parental alleles [77]. Importantly, our data clearly indicate the stochastic nature of all these genomic alterations, which is particularly visible among the independently formed allopolyploids.

We further observe an obvious tendency for allopolyploids to transcribe more fragments characteristic of the paternal $D$. incarnata than of the maternal $D$. fuchsii genome (significant at $P<0.001$, paired $t$-test), despite the similar number of diagnostic transcripts exhibited by the diploid species (the difference in the number of specific transcripts in progenitor species was rejected at $P=0.184$, independent samples $t$-test). This pattern contradicts the strong maternal bias reliably evident in most phenotypes of terrestrial orchids [78]. It may indicate that $D$. fuchsii genes are more often silenced/lost or that the rate of evolution of the maternal genome of allopolyploids is higher and more often results in novel cDNA fragments. This pattern contrasts with results in other systems - for example, in reciprocal hybrids of Oryza [43] - where allelic bias of gene expression in hybrids has been found to simply correlate with parental differences. On the other hand, a weak maternal expression dominance has been observed in the neopolyploid Spartina anglica [47].

Considering the fact that $D$. incarnata is a far more genetically homogeneous species than $D$. fuchsii $[49,50,72,79]$, an alternative explanation is that analyzed $D$. incarnata individuals are genetically more similar to the actual paternal progenitors of the allopolyploids than those on the maternal side. The difference between proportions of parent-specific fragments inherited in Dactylorhiza allopolyploids is generally consistent with genomic data [72]. However, at some loci, the converse trend is evident; ITS nuclear rDNA copies are generally converted towards the maternal parent in Dactylorhiza allopolyploids (with few exceptions, notably D. sphagnicola; [49]). Studies in other systems have shown that the relationship between gene copy number and expression is not always positive; for example, in Tragopogon neoploids, rDNA repeats of T. dubius origin are highly expressed and dominate rDNA transcription, even though homogenization has substantially reduced their copy number [80].

Another interesting aspect of the data obtained is that the number of cDNA-AFLP fragments transcribed in allopolyploid individuals (Table 2) was significantly higher compared with either progenitor lineage $(P<0.001$, independent samples $t$-test). Dactylorhiza majalis had on average 33\% more fragments than either diploid parental species, D. traunsteineri $27 \%$ more, and D. ebudensis $29 \%$ more; these figures may indicate an increase in the number of gene variants expressed in the allopolyploids. The difference observed is very similar with the pattern obtained comparing with RNA-seq the natural allopolyploid Glycine dolichocarpa and its diploid progenitors [81]. However, this pattern contradicts the widely held expectation that closely related organisms, independent of their ploidy, will express a similar number of genes in a given tissue in a shared environment at a particular moment in time - the underlying logic being that they are required to fulfil a similar number of functions. Hence, an increase in the number of fragments transcribed in allopolyploids provides evidence of an increase in complexity involving more extensive regulatory networks, subfunctionalization of expression between different leaf tissues, and/ or neofunctionalization $[23,82]$. Alternatively, both copies of duplicated genes may remain active and retain their original function over a long evolutionary time in polyploids if the relative gene-product stoichiometry is essential for appropriate cellular function or if the genes involved experience allele-dosage effects [83] that provide selective advantages. Many genes present in the genomes of extant angiosperms appear to have originated as a result of ancient polyploidization, especially many of those involved in development, transcriptional regulation and signaling $[6,23,84]$. The increase in number of such key genes is thought to have been of major importance for the evolution of biological complexity and the introduction of new phenotypic architecture in evolution [85].

Further, there was a marginally significant difference ( $P=0.045$, independent samples $t$-test) in the number of different transcripts amplified in individuals of the older allopolyploid D. majalis (average 230) and the cDNA markers in the younger D. traunsteineri and D. ebudensis (average 221). This trend may indicate that, with time, homeologs are re-activated and/or undergo more divergence via subfunctionalization or neofunctionalization. Such a pattern corroborates results of epigenetic investigations [86], revealing more methylation novelties in the $D$. traunsteineri genome than in D. majalis, which may be gradually reverting towards an epigenetic state closer to those of the parents.

\section{Increased transcriptomic variation within allopolyploids}

In addition to significantly more transcripts per profile, allopolyploid lineages show an extended range of transcript variability (illustrated by the increased space occupied by the allopolyploids in the transcriptomic landscape; Figure 3A). For example, diploid D. fuchsii samples from the eastern Alps and northern Pyrenees differ at only $12 \%$ of the expressed loci, but samples of D. majalis from the same regions differ at $29 \%$ of their (more numerous) loci. Products of clearly different 
polyploidization events can be even more divergent; there is up to $40 \%$ transcript difference between individuals of $D$. majalis and D. ebudensis. This may indicate a greater potential for expression plasticity of the allopolyploids resulting in phenotypic variability exceeding that found in either parent, thus indicating an adaptive advantage. However, this pattern is not mirrored in genomic AFLP data [72], where the differences between samples of parental species, and between samples from different allotetraploids, occupy a narrower interval (e.g. $43 \%$ differentiation within $D$. fuchsii and $49 \%$ between D. traunsteineri and D. majalis; see table 1 in [72]).

\section{Taxonomic and geographic differentiation of the allopolyploid transcriptomes}

The multiple independent origins of the tetraploids $D$. majalis and D. traunsteineri contribute to differential patterns of gene expression that show some geographic structure (Figure 3A). Several of the investigated transcripts are conserved within each allopolyploid taxon but are variable between taxa. The narrow-endemic Dactylorhiza ebudensis seems to integrate within the gene pool of D. traunsteineri (Figure 3B), but more studies are necessary for any taxonomic conclusions. At least $9 \%$ of the transcript data (the third vector obtained from the PCoA; Figure $3 \mathrm{~A}$ ) and the patterns within $\mathrm{NJ}$ (Figure $3 \mathrm{~B}$ ) clearly discriminate between the allotetraploid taxa. In contrast, the results of genomic AFLPs (mostly non-coding) do not provide clear clustering of allopolyploids relative to either geography or taxonomy [72]. This may indicate that habitat shapes similar expression patterns in some (but not all) of the independent allopolyploidization events, perhaps operating via epigenetic alterations under the effect of specific environmental pressures [48]. Given the present data, we cannot exclude the alternative hypothesis that the three allotetraploids may have been formed in situ by different parental types from within the diploid species, and thereby inherited distinct gene complexes already well-attuned to the appropriate habitats [87]. However, epigenetic investigations contradict the latter hypothesis [86].

\section{Polyploid adaptive segregation}

Allopolyploidy can have broad-scale effects on gene regulation and developmental processes; it is a source of novel phenotypes capable of prompting ecological diversification and new niche invasion [30]. In contrast with most other polyploid complexes, allotetraploid Dactylorhiza species do not exhibit broader geographical distribution ranges than their parents. The diploid species have extensive overall distributions, so that natural barriers (e.g. the Mediterranean and Nordic Seas) are likely to act as equally effective physical constraints on both diploids and polyploids, most probably through limiting distribution of appropriate mycorrhizae (e.g. [88]). However, allopolyploid lineages may have broader amplitudes in at least some ecological parameters than their individual diploid progenitors; for example, they apparently tolerate greater fluctuations in soil moisture than does D. incarnata. Their increased overall gene expression diversity and more numerous transcript variants within individuals are likely to contribute to more robust/complex regulatory networks and to heterosis, which may facilitate adaptation to novel conditions. Expression of duplicate genes diverges rapidly in response to changes in environmental (both abiotic and biotic) stresses, but relatively slowly in response to developmental changes that are associated with complex biological networks [89].

Polyploidy provides a vast reservoir of new alleles for mutation and selection, and hence is a prominent mechanism of speciation [14,30]. In general, WGD will immediately provide an allopolyploid with a high degree of postzygotic reproductive isolation from its diploid progenitors [12]. However, the products of recurrent allopolyploidization can suffer from a lack of isolation from each other. Given that they have the same ploidy and similar genomic heritage, maintenance of distinctiveness between independently formed sibling Dactylorhiza allopolyploids is likely to prove difficult in the face of substantial gene flow, though it is obviously possible. The most likely explanation is that, in Dactylorhiza, apparently weak reproductive isolation between allopolyploids is reinforced by considerable ecological divergence, perhaps inherited partly from distinct parental lines and partly via gene-expression differentiation. However, the balance between these two contrasting factors remains contentious, even among the present authors.

In any case, our analyses identify several of the transcriptomic patterns as being significantly correlated with native environmental conditions (Table 3, Figure 4). These are soon rendered adaptive, triggering and then maintaining ecological segregation between the allopolyploids. In this respect, BIO8 (mean temperature of the wettest quarter) appears to be one of the most relevant environmental factors exerting selective pressures among Dactylorhiza allopolyploids - it is involved in numerous significant regressions (Figure 5), including the most significant (Table 3). This conclusion receives further support from previous results of epigenetic investigations in this system [48]. BIO8 separates $D$. majalis from $D$. traunsteineri and D. ebudensis (Figure 4) and appears to be the primary epigenetic tool of divergent selection increasing their differentiation. Given the marsh-like habitats occupied by Dactylorhiza allopolyploids in general, we can easily find the biological interpretation of the adaptive function of a waterand temperature-related climatic parameter. Other important selective pressures seem to be exerted by 


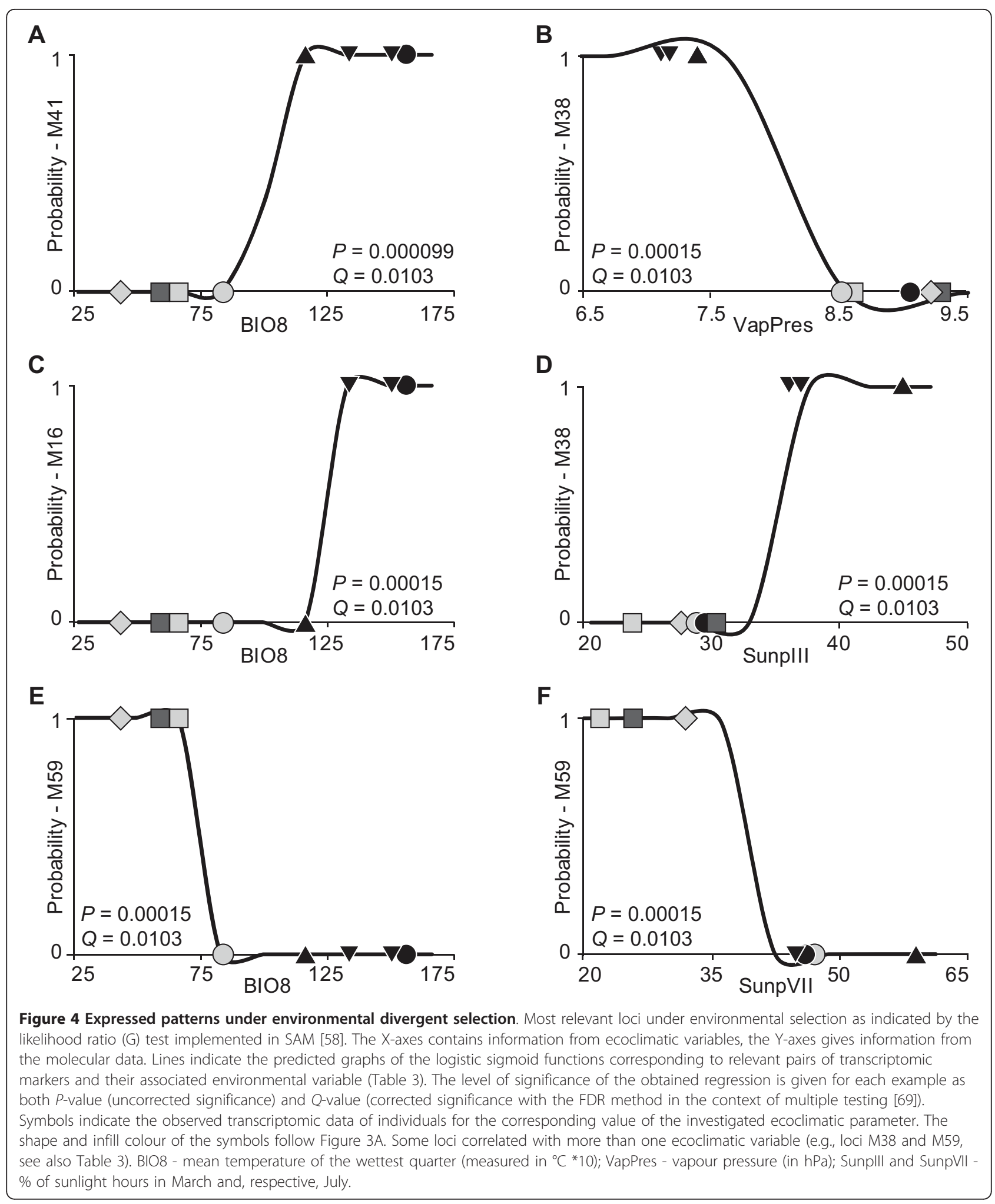




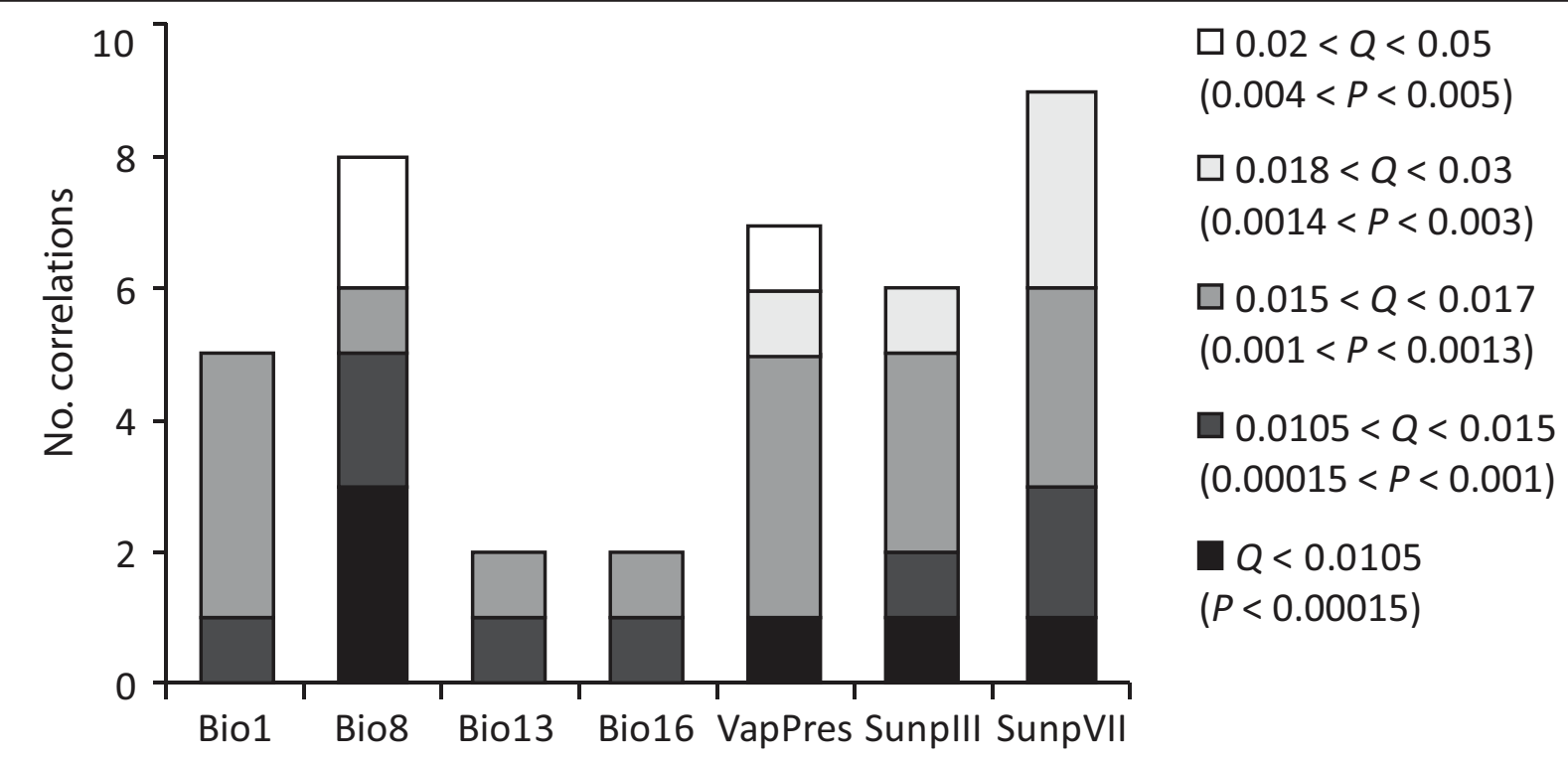

Figure 5 Environmental variables that exert a relevant selective pressure. Bar chart summarising the significant regressions obtained with SAM [58] (see also Table 3). The level of significance $(Q)$ is adjusted from $P$-values to control for type 1 errors with the FDR method [69]; only relationships with $Q<0.05$ are retained. Some markers are associated with several ecological variables (Table 3).

VapPres (vapour pressure) and SunpVII (\% of sunlight hours in July) (Table 3, Figures 4 and 5).

In general, there has been insufficient exploration of levels of gene-flow among co-occurring Dactylorhiza allotetraploids. In England and Wales, there is ostensibly a surprisingly narrow 'hybrid zone' occupied by the northern tetraploids $D$. purpurella and D. traunsteineri (as narrowly circumscribed in the British Isles by [50]) and the southern tetraploid D. praetermissa, which more closely resembles $D$. majalis genetically (e.g. [49]). The hybrid zone coincides with the Weichselian glacial maximum [50,90], suggesting an edaphic influence on their distributions in addition to latitude-related climatic clines. There is growing evidence of gradual southward expansion of D. purpurella and northward expansion of $D$. praetermissa into each others territory, with concomitant introgression [50], particularly in dune slacks and quarries [90]. Such populations merit detailed (epi) genetic and autecological investigation to determine the extent of gene flow and identify which factors have precluded more rapid migration.

\section{Conclusions}

Neutral genomic differentiation between Dactylorhiza allopolyploids is rarely clearly diagnosable [48-50,72]. This ambiguity contrasts with the surprisingly distinct expression patterns observed (Figure 3), although coding regions are generally expected to evolve much more slowly, and their epigenetic divergence is clear [48]. In the light of present and previous results [48], physical (genetic) diversification per se may be less relevant for allopolyploids; divergence between them may instead reside in quantitative partitioning of expression patterns, mainly via epigenetic changes that affect the level of expression of individual genes. Indeed, expression levels of a gene alone can determine phenotypes that contribute to the natural variation on which selection operates [91]. The key extrinsic factor responsible for the environmental selective pressures that are shaping adaptive expression patterns in Dactylorhiza allopolyploids seems to be a combination of water availability and temperature, perhaps in addition to $\mathrm{pH}$ and associated soil conditions. This conclusion is not surprising, given the moist equable habitats that these lineages usually occupy. Further studies of gene expression, combined with detailed exploration of the in situ ecological tolerances of diploid and allotetraploid taxa, should help to better understand the significance of iterative polyploid evolution and to identify the exact functions that are differently regulated in sibling lineages following recurrent hybridization and WGD.

\section{Additional material}

Additional file 1: The cDNA-AFLP data matrix and input file for SAM [58]. Excel file with one worksheet comprising the CDNA-AFLP binary data for diploid and polyploid individuals analysed here. A second worksheet includes the input for SAM [58].

\section{Acknowledgements}

We thank L Civeyrel, I Denholm and A Tribsch for help in collecting plant material, F Horsman for new information on the D. ebudensis locality, C Ryan 
for maintaining Dactylorhiza plants in cultivation, and M Frohlich, J Koh, I Leitch, B Sayers and D Soltis for helpful advice. C Parisod and an anonymous referee provided helpful comments that improved an earlier version of the manuscript. Natural England and the Forestry Commission England kindly provided collecting permits. This work was supported by an Intra-European Marie Curie Fellowship (DactGene, MEIF-CT-2007-040494) and an Austrian Science Fund (FWF) project (P22260-B16), both awarded to OP.

\section{Author details}

'Department of Systematic and Evolutionary Botany, University of Vienna,

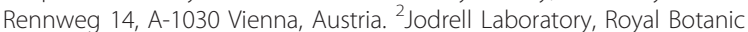
Gardens, Kew, Richmond, Surrey, TW9 3DS, UK. ${ }^{3}$ Department of Ecology, Section of Plant Ecology and Systematics, University of Lund, Lund, Sweden.

\section{Authors' contributions}

$\mathrm{OP}, \mathrm{RB}, \mathrm{MF}, \mathrm{MH}$ and $\mathrm{MC}$ designed the study and participated in collecting the samples. $J L$ genotyped samples at various loci prior to the CDNA analyses. OP performed the CDNA studies and most of the analyses. JM extracted the environmental data-points for the sampling localities from WorldClim. OP drafted the paper while RB provided the ecological context. $\mathrm{OP}$ and $\mathrm{RB}$ revised the manuscript. All authors read and approved the final manuscript.

Received: 28 December 2010 Accepted: 26 April 2011

Published: 26 April 2011

\section{References}

1. Van de Peer Y, Fawcett JA, Proost S, Sterck L, Vandepoele K: The flowering world: a tale of duplications. Trends Plant Sci 2009, 14:680-688.

2. Soltis DE, Albert VA, Leebens-Mack J, Bell CD, Paterson AH, Zheng C, Sankoff D, dePamphilis CW, Wall PK, Soltis PS: Polyploidy and angiosperm diversification. Amer J Bot 2009, 96:336-348.

3. Jackson S, Chen YJ: Genomic and expression plasticity of polyploidy. Curr Opin Plant Biol 2010, 13:153-159.

4. Blanc G, Wolfe KH: Widespread paleopolyploidy in model plant species inferred from age distribution of duplicated genes. Plant Cell 2004, 16:1667-1678.

5. Seoighe C, Gehring C: Genome duplication led to highly selective expansion of the Arabidopsis thaliana proteome. Trends Genet 2004, 20:461-464.

6. Maere S, De Bodt S, Raes J, Casneuf T, Van Montagu M, Kuiper M, Van de Peer Y: Modelling gene and genome duplications in eukaryotes. Proc Natl Acad Sci USA 2005, 102:5454-5459.

7. Kim S, Albert VA, Yoo MJ, Farris JS, Soltis PS, Soltis DE: Pre-angiosperm duplication of floral genes and regulatory tinkering at the base of angiosperms. Amer J Bot 2004, 91:2102-2118.

8. Veron AS, Kaufmann K, Bronberg-Bauer E: Evidence of interaction network evolution by whole-genome duplications: a case study in MADS-box proteins. Molec Biol Evol 2007, 24:670-678.

9. Pimm SL: The Balance of Nature Chicago: Chicago University Press; 1991.

10. DiMichele WA, Bateman RM: Plant paleoecology and evolutionary inference: two examples from the Paleozoic. Rev Paleobot Palyn 1996, 90:223-247.

11. Fawcett JA, Maere $S$, Van de Peer Y: Plants with double genomes might have had a better chance to survive the Cretaceous-Tertiary extinction event. Proc Natl Acad Sci USA 2009, 106:5737-5742.

12. Ramsey J, Schemske DW: Pathways, mechanisms, and rates of polyploid formation in flowering plants. Annu Rev Ecol Syst 1998, 29:467-501.

13. Coyne JA, Orr HA: Polyploidy and hybrid speciation. Speciation Sunderland, MA: Sinauer Associates; 2004, 321-351.

14. Paun O, Forest F, Fay MF, Chase MW: Hybrid speciation in angiosperms: parental divergence drives ploidy. New Phytol 2009, 182:507-518.

15. Sang T, Pan J, Zhang DM, Ferguson D, Wang C, Pan KY, Hong DY: Origins of polyploids: an example from peonies (Paeonia) and a model for angiosperms. Biol J Linn Soc 2004, 82:561-571.

16. Otto SP: The evolutionary consequences of polyploidy. Cell 2007, 131:452-462.

17. Parisod C, Holderegger R, Brochmann C: Evolutionary consequences of autopolyploidy. New Phytol 2010, 186:5-17.
18. Soltis DE, Soltis PS, Schemske DW, Hancock JF, Thompson JN, Husband BC, Judd WS: Autopolyploidy in angiosperms: have we grossly underestimated the number of species? Taxon 2007, 56:13-30.

19. Rieseberg LH, Archer AM, Wayne RK: Transgressive segregation, adaptation and speciation. Heredity 1999, 83:363-372.

20. Chen ZJ: Molecular mechanisms of polyploidy and hybrid vigor. Trends Plant Sci 2010, 15:57-71.

21. Comai L: The advantages and disadvantages of being polyploid. Nat Rev Genet 2005, 6:836-846.

22. Chapman BA, Bowers JE, Feltus FA, Paterson AH: Buffering of crucial functions by paleologous duplicated genes may contribute cyclicality to angiosperm genome duplication. Proc Natl Acad Sci USA 2006, 103:2730-2735.

23. De Bodt $\mathrm{S}$, Maere $\mathrm{S}$, Van de Peer $\mathrm{Y}$ : Genome duplication and the origin of angiosperms. Trends Ecol Evol 2005, 20:591-597.

24. Barringer BC: Polyploidy and self-fertilization in flowering plants. Amer $\rfloor$ Bot 2007, 94:1527-1533.

25. Paun O, Stuessy TF, Hörandl E: The role of hybridization, polyploidization and glaciation in the origin and evolution of the apomictic Ranunculus cassubicus complex. New Phytol 2006, 171:223-236.

26. Bateman RM, DiMichele WA: Generating and filtering major phenotypic novelties: neoGoldschmidtian saltation revisited. In Developmental Genetics and Plant Evolution. Edited by: Cronk QCB, Bateman RM, Hawkins JA. London: Taylor 2002:109-159.

27. Ramsey J, Schemske DW: Neopolyploidy in flowering plants. Ann Rev Ecol Syst 2002, 33:589-639.

28. Husband BC: Constraints on polyploid evolution: a test of the minority cytotype exclusion principle. Proc Royal Soc London B 2000, 267:217-23.

29. Stebbins G: Chromosomal Evolution in Higher Plants London: Edward Arnold 1971.

30. Otto SP, Whitton J: Polyploid incidence and evolution. Annu Rev Genet 2000, 34:401-437.

31. Wood TE, Takebayashi N, Barker MS, Mayrose I, Greenspoon PB, Rieseberg LH: The frequency of polyploid speciation in vascular plants. Proc Natl Acad Sci 2009, 106:13875-13879.

32. Chen ZJ: Genetic and epigenetic mechanisms for gene expression and phenotypic variation in plant polyploids. Annu Rev Plant Biol 2007, 58:377-406.

33. McClintock B: The significance of responses of the genome to challenge. Science 1984, 226:792-801.

34. Chague V, Just J, Mestiri I, Balzergue S, Tanguy AM, Huneau C, Huteau V, Belcram H, Coriton O, Jahier J, Chalhoub B: Genome-wide gene expression changes in genetically stable synthetic and natural wheat allohexaploids. New Phytol 2010, 187:1181-1194

35. Liu B, Brubaker CL, Mergeai G, Cronn RC, Wendel JF: Polyploid formation in cotton is not accompanied by rapid genomic changes. Genome 2001 44:321-330.

36. Adams KL, Wendel JF: Polyploidy and genome evolution in plants. Curr Opin Plant Biol 2005, 8:135-141.

37. Paun O, Fay MF, Soltis DE, Chase MW: Genetic and epigenetic alterations after hybridization and genome doubling. Taxon 2007, 56:649-656.

38. Doyle JJ, Flagel LE, Paterson AH, Rapp RA, Soltis DE, Soltis PS, Wendel JF: Evolutionary genetics of genome merger and doubling in plants. Annu Rev Genet 2008, 42:443-461.

39. Lee HS, Chen ZJ: Protein-coding genes are epigenetically regulated in Arabidopsis polyploids. Proc Natl Acad Sci USA 2001, 98:6753-6758.

40. Kashkush K, Feldman M, Levy AA: Gene loss, silencing and activation in a newly synthesized wheat allotetraploid. Genetics 2002, 160:1651-1659.

41. Adams KL, Wendel JF: Novel patterns of gene expression in polyploid plants. Trends Genet 2005, 21:539-543.

42. Hegarty MJ, Barker GL, Wilson ID, Abbott RJ, Edwards KJ, Hiscock SJ: Transcriptome shock after interspecific hybridization in Senecio is ameliorated by genome duplication. Curr Biol 2006, 16:1652-9.

43. He G, Zhu X, Elling AA, Chen L, Wang X, Guo L, Liang M, He H, Zhang H, Chen F, et al: Global epigenetic and transcriptional trends among two rice subspecies and their reciprocal hybrids. Plant Cell 2010, 22:17-33.

44. Marmagne $A$, Brabant $P$, Thiellement $H$, Alix K: Analysis of gene expression in resynthesized Brassica napus allotetraploids: transcriptional changes do not explain differential protein regulation. New Phytol 2010, 186:216-27. 
45. Tate JA, Ni Z, Scheen AC, Koh J, Gilbert CA, Lefkowitz D, Chen ZJ, Soltis PS, Soltis DE: Evolution and expression of homeologous loci in Tragopogon miscellus (Asteraceae), a recent and reciprocally formed allopolyploid. Genetics 2006, 173:1599-1611.

46. Buggs RJ, Elliott NM, Zhang L, Koh J, Viccini LF, Soltis DE, Soltis PS: Tissuespecific silencing of homoeologs in natural populations of the recent allopolyploid Tragopogon mirus. New Phytol 2010, 186:175-83.

47. Chelaifa H, Monnier A, Ainouche M: Transcriptomic changes following recent natural hybridization and allopolyploidy in the salt marsh species Spartina $x$ townsendii and Spartina anglica (Poaceae). New Phytol 2010, 186:161-74.

48. Paun O, Bateman RM, Fay MF, Hedren M, Civeyrel L, Chase MW: Stable epigenetic effects impact adaptation in allopolyploid orchids (Dactylorhiza: Orchidaceae). Molec Biol Evol 2010, 27:2465-2473.

49. Pillon Y, Fay MF, Hedrén M, Bateman RM, Devey DS, Shipunov AB, van der Bank M, Chase MW: Evolution and temporal diversification of western European polyploid species complexes in Dactylorhiza (Orchidaceae). Taxon 2007, 56:1185-1208.

50. Hedrén M, Nordström S, Bateman RM: Plastid and nuclear DNA marker data support the recognition of four tetraploid marsh-orchids (Dactylorhiza majalis s.l., Orchidaceae) in Britain and Ireland. Biol J Linn Soc 2011.

51. Nordström S, Hedrén M: Genetic diversity and differentiation of allopolyploid Dactylorhiza (Orchidaceae) with particular focus on the $D$. majalis ssp. traunsteineri/lapponica complex. Biol J Linn Soc 2009, 97:52-67.

52. Matzke M, Matzke AJ, Kooter JM: RNA: guiding gene silencing. Science 2001, 293:1080-1083.

53. Chen K, Rajewsky N: The evolution of gene regulation by transcription factors and microRNAs. Nat Rev Genet 2007, 8:93-103.

54. Lytle JR, Yario TA, Steitz JA: Target mRNAs are repressed as efficiently by microRNA-binding sites in the $5^{\prime}$ UTR as in the 3' UTR. Proc Natl Acad Sci USA 2007, 104:9667-9672.

55. Vos $P$, Hogers R, Bleeker M, Reijans M, van de Lee T, Hornes M, Frijters A, Pot J, Peleman J, Kuiper $M$, et al: AFLP: a new technique for DNA fingerprinting. Nucl Acids Res 1995, 23:4407-4414.

56. Bachem CWB, van der Hoeven RS, de Bruijn SM, Vreugdenhil D, Zabeau M, Visser RGF: Visualization of differential gene expression using a novel method of RNA fingerprinting based on AFLP: analysis of gene expression during potato tuber development. Plant J 1996, 9:745-753.

57. Bonin A, Bellemain E, Bronken Eidesen P, Pompanon F, Brochmann C, Taberlet $P$ : How to track and assess genotyping errors in population genetic studies. Molec Ecol 2004, 13:3261-3273.

58. Rohlf FJ: NTSYS-PC: Numerical Taxonomy and Multivariate Analysis System, 2.0.2 ed. Exeter Software 1997

59. Dice LR: Measures of the amount of ecologic association between species. J Ecol 1945, 26:297-302.

60. Nei M, Li WH: Mathematical model for studying genetic variation in terms of restriction endonucleases. Proc Natl Acad Sci USA 1979, 76:5269-5273

61. Felsenstein J: Confidence limits on phylogenetics: an approach using the bootstrap. Evolution 1985, 39:783-791

62. Van de Peer $Y$, De Wachter R: Construction of evolutionary distance trees with TREECON for Windows: accounting for variation in nucleotide substitution rate among sites. Comp Appl Biosci 1997, 13:227-230.

63. Joost S, Bonin A, Bruford MW, Conord C, Erhardt G, Taberlet P: A spatial analysis method (SAM) to detect candidate loci for selection: towards a landscape genomics approach to adaptation. Molec Ecol 2007, 16:3955-3969.

64. Joost S, Kalbermatten M, Bonin A: Spatial analysis method (SAM): a software tool combining molecular and environmental data to identify candidate loci for selection. Molec Ecol Res 2008, 8:957-960.

65. Hijmans RJ, Cameron SE, Parra JL, Jones PG, Jarvis A: Very high resolution interpolated climate surfaces for global land areas. Int J Climatol 2005, 25:1965-1978.

66. Moran MD: Arguments for rejecting the sequential Bonferroni in ecological studies. Oikos 2003, 100:403-405.

67. Garcia LV: Escaping the Bonferroni iron claw in ecological studies. Oikos 2004, 105:657-663.

68. Nakagawa S: A farewell to Bonferroni: the problems of low statistical power and publication bias. Behav Ecol 2004, 15:1044-1045.

69. Benjamini $Y$, Hochberg $Y$ : Controlling the false discovery rate - a practical and powerful approach to multiple testing. J Roy Stat Soc B Met 1995, 57:289-300.
70. Storey JD: A direct approach to false discovery rates. $J$ Roy Stat Soc B 2002, 64:479-498.

71. Lister R, O'Malley RC, Tonti-Filippini J, Gregory BD, Berry CC, Millar AH, Excker JR: Highly integrated single-base resolution maps of the epigenome in Arabidopsis. Cell 2008, 133:1-14.

72. Hedrén M, Fay MF, Chase MW: Amplified fragment length polymorphisms (AFLP) reveal details of polyploid evolution in Dactylorhiza (Orchidaceae). Amer J Bot 2001, 88:1868-1880.

73. Bateman RM, Hollingsworth PM, Preston J, Yi-Bo L, Pridgeon AM, Chase MW: Molecular phylogenetics and evolution of Orchidinae and selected Habenariinae (Orchidaceae). Bot J Linn Soc 2003, 142:1-40.

74. Devos N, Raspe O, Oh SH, Tyteca D, Jacquemart AL: The evolution of Dactylorhiza (Orchidaceae) allotetraploid complex: Insights from nrDNA sequences and cpDNA PCR-RFLP data. Molec Phylog Evol 2006, 38:767-778.

75. Pillon Y, Fay MF, Shipunov AB, Chase MW: Species diversity versus phylogenetic diversity: a practical study in the taxonomically difficult genus Dactylorhiza (Orchidaceae). Biol Cons 2006, 129:4-13.

76. Gaeta RT, Pires JC: Homoeologous recombination in allopolyploids: the polyploid ratchet. New Phytol 2010, 186:18-28.

77. Adams KL, Cronn R, Percifield R, Wendel JF: Genes duplicated by polyploidy show unequal contributions to the transcriptome and organspecific reciprocal silencing. Proc Natl Acad Sci USA 2003, 100:4649-4654

78. Bateman RM, Smith RJ, Fay MF: Morphometric and population genetic analyses elucidate the origin, evolutionary significance and conservation implications of Orchis $\mathrm{x}$ angusticruris (O. purpurea $\times 0$. simia), a hybrid orchid new to Britain. Bot J Linn Soc 2008, 157:687-711.

79. Hedrén M: Genetic differentiation, polyploidization and hybridization in northern European Dactylorhiza (Orchidaceae): evidence from allozymes markers. Plant Syst Evol 1996, 201:31-55.

80. Matyášek R, Tate JA, Lim YK, Srubarova H, Koh J, Leitch AR, Soltis DE, Soltis PS, Kovarik A: Concerted evolution of rDNA in recently formed Tragopogon allotetraploids is typically associated with an inverse correlation between gene copy number and expression. Genetics 2007, 176:2509-2519.

81. Coate JE, Doyle JJ: Quantifying whole transcriptome size, a prerequisite for understanding transcriptome evolution across species: an example from a plant allopolyploid. Genome Biol Evol 2010, 2:534-546.

82. Taylor JS, Raes J: Duplication and divergence: the evolution of new genes and old ideas. Annu Rev Genet 2004, 38:615-643.

83. Guo M, Davis D, Birchler JA: Dosage effects on gene expression in a maize ploidy series. Genetics 1996, 142:1349-1355.

84. Huminiecki $L$, Heldin C: $2 R$ and remodeling of vertebrate signal transduction engine. BMC Biology 2010, 8:146.

85. Kellogg EA: Evolution of developmental traits. Curr Opin Plant Biol 2004, 7:92-98.

86. Paun O, Luna JA, Fay MF, Bateman RM, Chase MW: Genomic responses drive adaptation in allotetraploid species of Dactylorhiza (Orchidaceae: Orchidinae). In Diversity, Phylogeny, and Evolution in the Monocotyledons. Edited by: Seberg O, Petersen G, Barfod A, Davis J. Århus: Aarhus University Press; 2010:169-192.

87. Bateman RM: How many orchid species are currently native to the British Isles? In Current Taxonomic Research on the British and European Flora. Edited by: Bailey JP, Ellis RG. London: Botanical Society of the British Isles; 2006:89-110.

88. Waterman RJ, Bidartondo M: Deception above, deception below: linking pollination and mycorrhizal biology of orchids. Ann Bot 2008, 59:1085-1096.

89. Chen ZJ, Ha M, Soltis D: Polyploidy: genome obesity and its consequences. New Phytol 2007, 174:717-720.

90. Bateman RM: Glacial progress: Do we fully understand the narrow-leaved marsh-orchids? New J Bot 2011.

91. Kalisz S, Purugganan MD: Epialleles via DNA methylation: consequences for plant evolution. Trends Ecol Evol 2004, 19:309-314.

doi:10.1186/1471-2148-11-113

Cite this article as: Paun et al:: Altered gene expression and ecological divergence in sibling allopolyploids of Dactylorhiza (Orchidaceae). BMC Evolutionary Biology 2011 11:113. 